\title{
Pueblos indígenas y justicia transicional en Guatemala. Comentario a Lieselotte Viaene, Nimla Rahilal. Pueblos indígenas y justicia transicional: reflexiones antropológicas
}

\author{
(2019) Deusto Digital \\ Bilbao, 166 pp.
}

\author{
Pedro Garzón López \\ Universidad Autónoma Benito Juárez de Oaxaca \\ garzonpedro27@hotmail.com
}
Cita recomendada:
Garzón López, P. (2020). Pueblos indígenas y justicia transicional en Guatemala. Comentario a Lieselotte Viaene, Nimla Rahilal. Pueblos indígenas y justicia transicional: reflexiones antropológicas. Eunomía. Revista en Cultura de la Legalidad, 18, pp. 392-396.

doi: https://doi.org/10.20318/eunomia.2020.5285

Recibido / received: 25/02/2020

Los pueblos indígenas constituyen uno de los actores internacionales que han planteado un fuerte cuestionamiento a diferentes paradigmas dominantes en el mundo occidental desde sus propias lógicas, cosmovisiones, filosofías, ontologías, epistemologías y sistemas normativos. De hecho, se afianzan como entidades portadores de nuevos paradigmas (Kuhn, 2001) en diferentes disciplinas y ámbitos del conocimiento moderno: cultura, derecho, poder, epistemología, justicia, etc. Si bien la perspectiva indígena no plantea muros infranqueables con la tradición occidental, puesto que desde la expansión colonial europea han coexistido dos cosmovisiones distintas que se influyen mutuamente, sí plantea lógicas distintas al contrastarla con disciplinas acomodadas en el mundo académico dominante. En el caso que nos ocupa, el trabajo de Lieselotte Viaene: Nimla Rahilal. Pueblos indígenas y justicia transicional: reflexiones antropológicas constituye una de las escasas reflexiones que desde el plano del análisis teórico-práctico cuestionan el paradigma dominante de la justicia transicional desde un lugar específico de la enunciación indígena: los pueblos mayas de Guatemala.

En efecto, el paradigma de la justicia transicional se ha afianzado globalmente como una medida reparativa para compensar a víctimas de graves violaciones a los derechos humanos en países que emergen de conflictos armados, cuyos «objetivos esenciales serían la búsqueda de justicia, recuperación de la verdad, reconciliación, reparación, garantías de no repetición y reformas institucionales» (Viaene, p. 22). A 
pesar de que los objetivos son variados y complejos, de acuerdo con la autora, el diseño de políticas gubernamentales tradicionalmente se ha limitado al modelo dominante de la justicia transicional desde las premisas liberales, eurocéntricas y legalistas del derecho internacional de los derechos humanos, soslayando una perspectiva indígena e intercultural que tome en cuenta los contextos locales de la cultura indígena, el rol de la justicia tradicional, así como el punto de vista de los supervivientes, sus epistemologías, ontologías, cosmovisiones, etc.

El discurso hegemónico de los derechos humanos ha sido la piedra angular para rendir cuentas por las atrocidades cometidas durante más de tres décadas de violaciones sistemáticas a los derechos de los indígenas mayas en Guatemala, periodo durante el cual no solo se vulneraron derechos individuales sino colectivos de pueblos y comunidades enteras. Por esta razón, la autora plantea que la justicia transicional tiene que ensanchar sus estrechos límites centrados en el individuo/victima/victimario, que solo busca que los responsables sean enjuiciados en los tribunales estatales o internacionales a fin de que las atrocidades cometidas no queden impunes. Esta situación contrasta -a decir de la autora- con la cosmovisión del pueblo q'eqchi': "Las normas de la justicia q'eqchi' no buscan la persecución judicial y el encarcelamiento de los responsables de estas violaciones, pues de esto se ocupa la lógica interna del cosmos que forma parte del sistema normativo indígena q'eqchi» (Viaene, p. 95). De modo que un modelo de justicia transicional con perspectiva indígena debe abrirse a otras disciplinas de estudio como la antropología jurídica, el derecho indígena, el pluralismo jurídico, la interculturalidad y, sobre todo, tener en cuenta el marco de referencia cultural de los destinatarios de políticas de justicia con enfoque intercultural y que sea diseñado «desde abajo» y no al revés.

Desde luego compartimos la critica que esboza la autora al modelo tradicional de la justicia transicional diseñado desde arriba y monopolizado por el eurocéntrismo y la visión antropocéntrica del individuo y sus derechos, especialmente cuando un rasgo que caracteriza a los pueblos indígenas es que sus sistemas normativos de autorregulación no se entienden de manera aislada, sino que forman parte de una concepción holística en el que predominan valores que armonizan las relaciones comunitarias con los seres humanos, la naturaleza y la espiritualidad. Se trata de un derecho sustancial estructurado en función de la cultura, la identidad, el territorio, el poder comunitario, la naturaleza, la religión, etc. Todos estos marcadores proveen en su conjunto de una serie de valores, hechos, normas, espiritualidades y cosmovisiones mejor sintetizadas en el principio de la comunalidad ${ }^{1}$, por diferenciarlo de la individualidad occidental. En este sentido me parece que el libro de Lieselotte logra poner los puntos sobre las «ies» al cuestionar la visión académica dominante de la justicia transicional a través de argumentos teóricos y empíricos a partir de estudios de casos de sobrevivientes que experimentaron un profundo sufrimiento y dolor (nimla rahilal) durante el conflicto armado interno en Guatemala.

Ciertamente uno de los puntos nodales que dificulta la armonización entre la cosmovisión occidental y la indígena -lo que afecta desde luego a la concepción e implementación del paradigma dominante de la justicia transicional- estriba en que la

\footnotetext{
${ }^{1}$ La comunalidad es la lógica en que se estructura y funciona la vida comunitaria, siendo algunas de sus expresiones: el tequio, la asamblea, el sistema de cargos, el sistema normativo propio, fiestas y tradiciones, el territorio. De hecho existe un movimiento comunalista iniciado por pensadores indígenas mixes y zapotecos de la sierra de Oaxaca, México. De acuerdo con Floriberto Díaz (2001): "La comunalidad expresa principios y verdades universales en lo que respecta a la sociedad indígena, la que habrá de entenderse de entrada no como algo opuesto sino diferente a la sociedad occidental. Para entender cada uno de sus elementos hay que tener en cuenta ciertas nociones: lo comunal, lo colectivo, la complementariedad y la integralidad. Sin tener presente el sentido comunal e integral de cada parte que pretendamos comprender y explicar, nuestro conocimiento estará siempre limitado».
} 
cosmovisión indígena está trazada por el carácter colectivo, complementario, integral y holístico de sus «epistemologías enclavadas en sus ontologías» (Viaene, p. 30), en donde no hay una separación tajante entre seres humanos, naturaleza y espiritualidad, sino que todo es uno, interdependiente y está interrelacionado. Es así como los seres humanos, las montañas, los ríos, los manantiales, las plantas, los animales, lugares sagrados, etc., constituyen el sustrato de los derechos humanos colectivos. Sin embargo, estos conocimientos, filosofías o saberes indígenas han sido encubiertos o invisibilizados por el conocimiento eurocéntrico como bien ha sido ilustrado por Lieselotte, al señalar la existencia de una «brecha de conocimiento» que impide comprender la cosmovisión y ontologías de los indígenas mayas. En consecuencia, esto plantea la necesidad de descolonizar la justicia transicional y los derechos humanos más allá de sus límites tradicionales; sobre todo, si tenemos en cuenta que el monopolio del eurocentrismo se ha centrado en la distinción entre lo verdadero y lo falso en el campo del conocimiento científico, y desde esta premisa, los pueblos indígenas no tienen conocimientos verdaderos sino creencias, magia, idolatría, comprensiones intuitivas o subjetivas. De igual manera, el campo del derecho ha sido determinado por lo legal y lo ilegal según el derecho occidental, mientras que en los pueblos indígenas solo hay usos y costumbres, o en todo caso, un vacío jurídico, lo alegal por ser un territorio sin ley (Santos, 2010, pp. 29-32).

Ahora bien, en el discurso teórico se reconoce la diferencia cultural y se invoca el pluralismo cultural y el multiculturalismo como mecanismos que posibilitan el encuentro y el dialogo intercultural, no solo entre dos visiones culturales distintas, sino entre el Estado y los pueblos indígenas. Además, existe ya un catálogo de derechos colectivos en el derecho internacional de los derechos humanos que reconoce el derecho a la diferencia cultural, la justicia y el pluralismo jurídico, la consulta previa, libre e informada, derecho a la tierra, el territorio y los recursos naturales, etc. Todos estos derechos en su conjunto sustancian el derecho a la autonomía y libre determinación indígena (Anaya, 2005). A pesar de que este conjunto de derechos resultan novedosos y progresistas frente a la ortodoxia liberal reacia al reconocimiento de derechos en función de grupos, en la práctica sigue dominando el pensamiento eurocéntrico, el individualismo y la cultura jurídica occidental en la interpretación y aplicación de los derechos indígenas, lo cual dificulta materializar la autodeterminación sustancial de los pueblos indígenas (Garzón López, 2016).

La propuesta de Lieselotte Viaene es creativa en sus planteamientos metodológicos, empíricos y argumentativos, aun cuando puede haber espacios inexplorados y que es oportuno traslucirlo desde el enfoque de la colonialidad del poder y la colonialidad del derecho, puesto que pensamos que la diferencia entre los pueblos indígenas y el Estado no solo es cultural, sino también colonial. Si bien el enfoque intercultural amplia el ángulo de visión de la justicia transicional, no obstante, se deja intacta las relaciones de poder entre los pueblos indígenas y el Estado como aparato reproductor del eurocentrismo y de la colonialidad/modernidad occidental. Desde esta premisa, la relación entre el Estado y los pueblos indígenas sigue siendo una relación colonial presente desde la expansión colonial europea en las Américas. De ahí que las políticas multiculturales de reconocimiento de derechos colectivos y de la interculturalidad no hayan logrado transformar las relaciones de dominación que experimentan actualmente los pueblos indígenas; por el contrario, muchas veces el discurso de reconocimiento multicultural no solo ha neutralizado el potencial emancipador de los pueblos indígenas en cuanto sujeto político colectivo, sino que además, ha contribuido a legitimar las relaciones de dominación sobre los pueblos indígenas.

Por otro lado, a nuestros días existe un avance significativo del reconocimiento indígena -limitado predominantemente por una visión liberal de los derechos- al 
haber una serie de derechos cuya aplicación tomada en serio, debería condicionar un punto de inflexión a la justicia transicional en perspectiva indígena y decolonial. En este contexto, también la diferencia entre el derecho indígena y el derecho occidental no solo es de naturaleza cultural, sino además, colonial. Desde la "diferencia cultural" se busca un mejor entendimiento entre culturas diferentes a través de la interpretación intercultural del derecho. En cambio, desde "la diferencia colonial" se plantea un distanciamiento de la gramática jurídica eurocéntrica y buscar desvelar la colonialidad jurídica presente en la teoría y práctica del derecho occidental. De ahí que la dimensión intercultural del derecho resulta apenas la punta del iceberg, es preciso ahondar su análisis desde el enfoque de la "diferencia colonial" y cuestionar así la «colonialidad jurídica» que subyace en la gramática jurídica moderna, la cual no solo se expresa en la ciencia jurídica y en las decisiones judiciales, sino también en la legislación, en las normas, prácticas, valores, hábitos, símbolos y razonamientos de los operadores del sistema jurídico-político dominante (Garzón López, 2019).

Lo anterior se pone de manifiesto dado que, de la lectura del trabajo de Liesolette Viaene, se deduce una importante intersección entre cultura y derecho como marcadores analíticos que recorren a lo largo de sus argumentos críticos contra la visión dominante de la justicia transicional, posición con la cual no puedo estar en desacuerdo, por el contrario, me parece que la autora logra sincronizar muy bien argumentos teórico-académicos con la descripción empírica localizada. No obstante, considero oportuno añadir la dimensión del poder, puesto que entendemos que subsiste una visión colonizante que ha justificado relaciones estructurales de dominación hacia los pueblos indígenas. Por esta razón, muchas políticas que se han diseñado pensando en los pueblos indígenas han sido políticas coloniales de reconocimiento que sólo han reforzado las estructura de dominación en el seno de los modernos Estados coloniales. Desde el pensamiento decolonial, la trilogía modernidad, capitalismo y eurocentrismo se conciben como procesos coetáneos que significaron el horizonte colonial en América Latina, y que a partir del siglo XVI se constituyeron como ejes centrales de dominación sobre la población del "nuevo mundo". Estos son los componentes básicos que están en la base de lo que Quijano denomina «colonialidad del poder» (2007, p. 93), en tanto patrón de dominación/explotación/control entre colonizadores y colonizados. Este patrón de poder colonial está organizado fundamentalmente sobre la idea de raza/etnia y atraviesa diferentes planos y dimensiones de la vida social: poder, trabajo, conocimiento, economía, autoridad, género, etc.

En definitiva, lo que se pretende poner en el debate es que si bien el paradigma dominante de la justicia transicional está atravesado por el pensamiento eurocentrista y la cultura jurídica occidental de base individualista, una perspectiva indígena en clave intercultural y ontológica sin duda puede contribuir en localizar procesos de justicia transicional teniendo en cuenta el punto de vista interno de los sujetos involucrados; no obstante, tratándose de pueblos con una historia colonial y con relaciones estructurales de dominación basados en la desigualdad social, el racismo y la violencia, cuestionarlo desde el eurocentrismo y el antropocentrismo no son suficientes sin desvelar la colonialidad, la modernidad y el capitalismo que son coordenadas de análisis que no se traslucen directamente en la violencia sufrida por los pueblos indígenas de Guatemala, pero que tienen sus explicaciones y causas más profundas en la reproducción de una suerte de "colonialismo interno" ${ }^{2}$ en la mentalidad de quienes infligieron violencia física, moral y psicológica.

\footnotetext{
2 Al efecto, véase González Casanova, P. (1975), La democracia en México, Era, México; Stavenhagen, R. (1981), "Siete tesis equivocadas sobre América Latina", Sociología y subdesarrollo, Nuestro tiempo, México, pp. 15-84; Bonfil Batalla, G. (1972), "El concepto de indio en América: una categoría de la situación colonial”, Anales de Antropología Vol. IX, México, Instituto de Investigaciones Antropológicas
} 


\section{Bibliografía}

Anaya, J. (2005). Los pueblos indígenas en el derecho internacional, Madrid, España: Trotta/Universidad Internacional de Andalucía.

Bonfil Batalla, G. (1972). El concepto de indio en América: una categoría de la situación colonial, Anales de Antropología Vol. IX, México, Instituto de Investigaciones Antropológicas de la UNAM, México, D. F. pp. 105-124.

Díaz Gómez, F. (2001). "Comunidad y comunalidad" en Jornada semanal № 314, 11 de marzo, México D.F.

Garzón López, P. (2019). Pluralismo jurídico, jurisdicción y colonialidad jurídica: alcances y límites del reconocimiento indígena. En: Garzón López, P. y Mejía Mesa, O. (Coords.), Pueblos indígenas y Estado: avances, límites y desafíos del reconocimiento indígena (pp. 233-260). Quito, Ecuador: Abya Yala.

Garzón López, P. (2016). Ciudadanía indígena. Del multiculturalismo a la colonialidad del poder, Prólogo de José María Sauca Cano, Madrid, España: Centro de Estudios Políticos y Constitucionales.

González Casanova, P. (1975). La democracia en México, México: Era.

Kuhn, T. S. (2001). La estructura de las revoluciones científicas, trad. de Agustín Contín, Madrid, España: Fondo de Cultura Económica.

Quijano, A. (2007). Colonialidad del poder y clasificación social. En Grosfoguel R., y Castro-Gómez, S. (eds.), El giro decolonial. Reflexiones para una diversidad epistémica más allá del capitalismo global (pp. 93-126), Bogotá, Colombia: lescoPensar-Siglo del Hombre Editores.

Rivera Cusicanqui, S. (2010). Ch'ixinakax utxiwa: Reflexión sobre prácticas y discursos descolonizadores, Buenos Aires, Argentina: Ediciones Tinta Limón.

Santos, B. de S. (2010). Descolonizar el saber, reinventar el poder, Montevideo, Uruguay: Trilce/Extensión Universitaria.

Stavenhagen, R. (1981). Siete tesis equivocadas sobre América Latina, Sociología y subdesarrollo, Nuestro tiempo, México, pp. 15-84.

de la UNAM, México, D. F. pp.105-124, Rivera Cusicanqui, S. (2010). Ch’ixinakax utxiwa: Reflexión sobre prácticas y discursos descolonizadores, Ediciones Tinta Limón, Buenos Aires. 